\title{
"We are a Motley Crew": Exploring the Careers of Men and Women Working at the University-Industry Interface
}

\author{
Juliane Achatz', Stefan Fuchs², Corinna Kleinert ${ }^{3}$, Simon Roßmann ${ }^{4}$
}

\begin{abstract}
Entrepreneurial activities of faculty have received increasing research attention. In contrast, little is known about the careers and activities of the women and men working at the university-industry interface. To close this gap, in this paper we address technology transfer as an emerging occupational field and examine the careers of people working in the field. Taking the example of Germany, we show that on the surface technology transfer is almost perfectly gender balanced, but marked gender differences exist between and within transfer organizations. Against this background, we find a 'motley crew' with a diversity of disciplinary backgrounds and professional experiences. While women often consider working in technology transfer as temporary in nature and 'second best' when compared to a science career, men approach their career in an entrepreneurial spirit. Our results also suggest that women's opportunities and gains are fragile because of the still transitory nature of the field.
\end{abstract}

Keywords: technology transfer; careers; gender.

\footnotetext{
I Institute for Employment Research, (IAB) Nuremberg of the German Federal Employment Agency (BA) Regensburger Strasse 104, D-90478 Nuremberg. Phone: +49 (0)9II 179 2527. Email: juliane.achatz@iab.de

2 Institute for Employment Research, (IAB) Nuremberg of the German Federal Employment Agency (BA) Regensburger Strasse 104, D-90478 Nuremberg. Phone: +49 (0)9II 179 3539. Email: stefan.fuchs@iab.de

${ }^{3}$ Institute for Employment Research, (IAB) Nuremberg of the German Federal Employment Agency (BA) Regensburger Strasse 104, D-90478 Nuremberg. Phone: +49 (0)9। I 179 |479. Email: corinna.kleinert@iab.de

${ }^{4}$ WZB (Social Science Research Center, Berlin) Reichpietschufer 50, D-10785 Berlin. Phone: +49 (0) 302549 I -233.

Email: rossmann@wzb.eu
} 


\section{Introduction}

Research on technology transfer and on determinants of entrepreneurial activities of faculty have traditionally played an important role in the context of 'triple helix' and 'third stream' activities of universities - often with a focus on changes in professional norms and professionals' perceptions of the rise of commercial science (Leydesdorff and Etzkowitz 1998; Crespi et al. 2007; Krücken 2003). At the same time, the number of studies on the gender dimension in academic entrepreneurship has been growing, with almost all finding significant gender differences in transfer activities of university faculty both within and between cohorts of academics (Murray and Graham 2007; Stephan and El-Ganainy 2007; Whittington and SmithDoerr 2005; Corley and Gaughan 2005; Thursby and Thursby 2005).

However, with a few notable exceptions, the intersection of technology transfer and gender is curiously absent from the literature. For instance, Murray and Graham (2007) observed in their study of faculty's engagement in transfer activities that male scientists interacted with technology transfer organizations mainly for legal support, administrative and management issues, feeling "that this third-party broker had little additional impact on their ability to link to established companies". In contrast, female scientists used technology transfer organizations more often and described "the 'hand holding' provided [...] as guiding them through an uncertain landscape" (ibid. p. 67I). While generally being optimistic about a positive effect of technology transfer organizations on the commercial activities of female scientists, the authors remain cautious that technology transfer organizations may themselves have a gender bias or their activities may "reinforce instead of undermine the gender gap" (ibid. p. 68I) in technology transfer.

In this paper we address the roles of professionals in the interface professions between science and the economy. ${ }^{5}$ We analyze technology transfer as an emerging occupational field in Germany and observe the careers of men and women working therein. More specifically, we

${ }^{5}$ This research is part of the international research project WIST (Women in Innovation, Science and Technology). We owe our partners a great deal: Doina Banciu and Nicoleta Dumitrache (NCPM, Romania); Oili-Helena Ylijoki, Marja Vehiläinen, and Pia Vuolanto (TasTI, Tampere University, Finland); Henry Etzkowitz, Marina Ranga, and Cheryl Conway (Newcastle University, UK). examine how technology transfer professionals define and enact their careers and how they cope with and succeed in their work. We argue that by looking at it from a women's careers in science perspective, technology transfer makes a particular interesting case to examine whether women successfully 'reappear from the 'leaky pipeline' in sciencerelated occupations that have opened up as a result of the increasing economic and social relevance of science" (Etzkowitz et al. 2008).

From following the careers of women and men who 'disappear from' or 'drop out' of science, we expect a better understanding of barriers in science, in particular those that women face. We also anticipate that we will learn something about the costs and benefits of leaving science - be it in monetary terms or with regards to professional identities and occupational challenges. To capture the dynamics of women's reappearance from the "leaky pipeline" and promising careers in technology transfer, we draw on three arguments:

(a) Newness of the field;

(b) Female labour pool and skills;

(c) Favourable organizational structures.

\section{a. Newness of the Field}

The institutionalization of technology transfer is a recent activity - at least at many universities, and particularly so in Germany, where the first technology transfer offices at universities were established in the 1980s, many as late as during the 2000s. Because technology transfer has grown in importance in recent years, so has the demand for professionals in the field at a time when the pool of female academics is still steadily increasing. The status of technology transfer in Germany is best described as a 'new' or 'emerging' occupational field (Crosby 2002) at an early stage of professionalization (Owen-Smith 2007). Typically, at this stage there are still relatively few professionals; tasks and services are broadly defined; there are few everyday working routines, and there is as yet no specific education or training. Thus the field offers employment prospects for a 'motley crew' of academics of various backgrounds. Technology transfer offers career opportunities that are close to, but not in science, requiring academic background and experience all the same. Given enough eligible and interested women

ISSN: 07I 8-2724. (http://www.jotmi.org)

Journal of Technology Management \& Innovation (C) Universidad Alberto Hurtado, Facultad de Economía y Negocios 
scientists at the outset of the institutionalization of technology transfer at universities, barriers to their entry should be low: we may assume that the 'traditional' gender hierarchy identified in science does not apply (yet), and we may expect that male and female scientists in the field define their roles in comparison to a career in science regarding, for example, openness towards detours and moves to and fro from science to industry.

\section{b. Female Labour Pool and Skills}

Usually, technology transfer organizations are staffed with a mix of highly qualified employees with both scientific and business backgrounds (Markman et al. 2005; Siegel et al. 2003, 2007; Murray and Graham 2007). These 'experts' are no longer or have never been engaged in research and development of new technologies, but understand, support and manage the 'commercial science marketplace', provide services for founders or inventors, or act as intermediaries between academia and business. Thus, technical and nontechnical 'people management' skills that are required in doing transfer work are often seen as favourable to the inclusion of women. Nevertheless, although helpful regarding women's entry into the field, the belief that women's skills are of particular value potentially deepen already existing gender stereotypes and intensify gender segregation in technology transfer.

\section{c. Favourable Organizational Structures}

Like start-up companies or new high-tech firms (see e.g. Baron et al. 2002), technology transfer offices are usually young and small, with flat hierarchies and the bulk of work typically organized in and around projects. Regarding working conditions in technology transfer, flexibility in terms of time and space is substantial, even if the workload is also considerable, because resources are usually scarce and the personnel situation is tight. For example, SmithDoerr (2004a, 2004b) found that organizational structures and demographics in young biotechnology firms appear to work in favor of female scientists. Network organization, project-based teams, flat hierarchies and multiplex relations with external collaborators - all contributed to better career prospects for female scientists than comparable, but more hierarchical and bureaucratic organizations. Finally, in most technology transfer units in Germany part-time jobs are quite common. Jobs such as these are attractive especially for highly qualified working mothers and may be one reason for the overall high share of women in the field when compared to the respective proportion of women among faculty and research staff at the same institutions. Between and within technology transfer organizations, however, there are similarities and marked differences: while the majority of the decisionmaking personnel are male, female scientists are represented to a larger extent at the transfer offices of (public) universities than at the (more professionalized) units at prestigious umbrella research organizations.

One caveat needs be emphasized here, though: evolving or new organizational structures may also work to the disadvantage of women scientists. Baron et al. (2007) analyzed gender inequality in high-tech start-up firms and found that their founders' initial conceptions of employment relations strongly shaped their subsequent demographic composition, particularly regarding the presence of women in 'core roles'. Firms founded along 'commitment lines', i.e. network- and project-based, were less likely to retain women than firms founded along bureaucratic lines. Thus the newness of technology transfer organizations makes their structures prone to change, and they may be disbanded easier than more established organizational forms. In return we may expect career prospects to be even less clear and promotion opportunities fewer than in older, larger academic organizations with a more differentiated positional structure. A lack of decision-making positions may be particularly problematic for the (mainly female) pool of part-time employees.

The remainder of the paper is organized as follows: Section 2 discusses the research design and methods applied. In section 3 we provide some key facts about the organizational context of and the representation of women in the German technology transfer sector. Our results are presented in section 4, as follows: in section 4.1 we describe three types of entryways into technology transfer: accidental, strategic, and forced. Against this background and across type of entry, section 4.2 addresses the question how working in technology transfer is perceived when compared to a career in science. In section 4.3 we focus on career issues in technology transfer predominantly addressed by the females we interviewed, i.e. part-time work and the reconciliation of work with domestic responsibilities. Finally, in section 5 we draw some conclusions. 


\section{Design and Methods}

Siegel and colleagues observed that in terms of data and methods, academic entrepreneurship "is an interdisciplinary topic, which can be studied using mixed methods" (2007: 490). In their taxonomy of the literature, Rothaermel et al. (2007: 700) concluded that "most studies on university entrepreneurship tend to be more qualitative in nature", probably because of a lack of suitable data. Of the literature reviewed, 93 articles or 54 percent were classified as case studies or used other qualitative methods (ibid. 70I). And only a "few existing studies focus on the intersection of elements", e.g. between the university system and technology transfer offices (ibid. 708) or technology transfer organizations in particular. The authors also considered most of the research to be "atheoretical", i.e. "indicative of a field in the embryonic stage of development" (ibid. 706), where there is more interest in theory- building than in theory-testing and qualitative methods are used for exploratory reasons.

The data used in this paper was collected in the same direction. The study reported in this paper is part of the international research project 'Women in Innovation, Science and Technology' (WIST), which examined participation and career advancement of women in technology transfer in the UK, Finland, Germany, and Romania. In Germany, in 2007 we interviewed a total of 40 employees of technology transfer offices, including 6 CEOs (see Table I). We selected our interview partners from a representative sample of technology transfer organizations, located in two metropolitan areas characterized by a critical mass of universities and other organizations engaged in transfer activities. Our selection of interview partners mirrors the German technology transfer architecture (for details see section 3 ).

\begin{tabular}{cc}
\hline Universities & 18 \\
Universities of Applied Science & 6 \\
Umbrella Research Organizations & 9 \\
Nexus Organizations & 7 \\
\hline
\end{tabular}

Table I. Institutional location of interviews WIST Germany (2007)

The interview method we used was expert interviews in the wide sense proposed by Meuser and Nagel (1994), i.e. interviewing people who "have specific knowledge and skills due to their occupational status" (see Moyser 1988). The semi-structured interviews covered issues like: the work history and science career of the interviewees, their current tasks and their past experiences in technology transfer organizations. In addition, the interviewees were asked to assess technology transfer as a profession, gauge career opportunities, and describe the importance of networks and networking in the field. The interviews also dealt with gender segregation and work-life-balance issues in technology transfer from a personal and an institutional perspective. At the end of each interview, all interviewees were asked whether they would fill out a short form on their employment history and return the form after completion.

On average, the interviews took 60 minutes, and most of the interviewees were very interested in the project. Gender issues were rarely addressed by the interviewees and if so, it was mainly to declare gender a non-issue in technology transfer. All interviews were recorded digitally and afterwards transcribed verbatim. We then grouped the interview data thematically, categorized and coded each case in joint analytical sessions to trace individual career paths into technology transfer and draw information on the different organizational structures and working conditions in the field. For reasons of brevity we abandoned all longer verbatim quotes in this paper and provided shorter quotes from the interviews (").

\section{Organizational Context and Representation of Women in German Technology Transfer}

The German technology transfer sector is split into four parts:

(i) First, there are the traditional and technical universities. 
(ii) Second, there are universities of the applied sciences, which are also involved with teaching, but to a much larger extent than the previous two categories of universities and with considerably lower obligations on the research side. In both types of universities, transfer activities have been historically carried out at the individual or departmental level and were institutionalized late by international standards.

(iii) Third, there is a strong non-university research sector with approximately 230 research institutes assembled under the roof of four umbrella organizations Max-Planck-Society, Fraunhofer Society, Helmholtz Society, and Leibniz Association. Each organization has a division devoted to technology transfer and the promotion of commercially relevant research.

(iv) Finally, there is a broad range of 'nexus' organizations usually with strong ties to the academic institutions in the particular region, building a roof for diverse transfer activities such as incubators, science parks, and cluster-specific networks.

Against this background, 'technology transfer' is a label covering a wide range of activities. We find that almost all of these activities are - in one way or another - taken care of within each organization. However, the level of professionalization and the amount of tasks differ. We find that these differences between technology transfer offices are far from arbitrary, but reflect the organisational size, structures and missions of the distinct organisational types. The 'classic' transfer of new technologies through patenting, licensing and spin-offs is found particularly at umbrella organisations, centralised and conducted by specialized transfer units. At universities of applied sciences, personal ties to industry of professors play a more dominant role than transfer offices. Both the other universities and network organisations represent a broader approach to technology transfer including further training and regional business marketing. The support and funding of businesses and spin-offs are also important activities of transfer units at universities and nexus organizations

Table 2 shows the range of women's average representation in technology transfer organizations and among faculty in the organizations we observed in our study. Undeniably, there is a strong female presence, in particular when compared to the respective proportion among faculty and researchers at each institution. However, the overwhelming majority of the decisionmaking and leading personnel in the technology transfer organizations examined are male. Furthermore, females are represented to a larger extent in the technology transfer offices of universities and nexus organizations than in the transfer units of the prestigious umbrella research organizations with their narrower focus on 'hard' transfer tasks and services, a higher level of professionalization, and longer organizational history.

\begin{tabular}{lll}
\hline & $\begin{array}{l}\text { Female academic staff in technology } \\
\text { transfer organizations }\end{array}$ & Female faculty \\
\hline Universities & $45 \%-75 \%$ & $25 \%-28 \%$ \\
Universities of Applied Science & $38 \%-50 \%$ & $17 \%-21 \%$ \\
Umbrella Research Organizations & $13 \%-44 \%$ & $19 \%-32 \%$ \\
Nexus Organizations & $41 \%-100 \%$ & Not applicable \\
\hline
\end{tabular}

Table 2. Representation of women in four organizational fields

These differences probably reflect the fact that umbrella research organizations connect the transfer activities of institutes in science and engineering with an already low proportion of women within their ranks. Since the focus of activities is almost exclusively on licensing and patenting, another possible explanation is that the bulk of transfer work at umbrella research organizations in Germany involves male clients among innovators and in industry, a scenario that could result in women's lower participation because of a (tacit) preference for same-sex settings in technology transfer activities.

\section{Results: Gendered Careers in Technology Transfer}

In technology transfer organizations, work is usually done in small teams, often consisting of two or three persons with a single CEO or supervisor within the organization. 
While supporting a general feeling of high responsibility and serious participation in decision-making, the resulting flat hierarchies have important career consequences since opportunities for within-firm advancement are rare or absent. Regarding working conditions, part-time work is quite common and flexibility in terms of time and space is considerable - features considered advantageous by our interviewees throughout. Employment on a contract to contract basis and relatively low wages were considered as detrimental to a career in technology transfer, in particular at the German universities where uniform salaries for public servants are negotiated on the state or national level. In addition, most interviewees considered their degrees of freedom in flexibility to be taken by a high and demanding workload.

Generally, we find our interviewees' career histories marked by traces of the 'nomadic', 'boundary-less' or 'portfolio' careers typical for the service industry or the information and communications technology (Valgaeren 2005; Légault and Chasserio 2006). Among its prominent features is a continuous building up of qualifications and experience, as well as a readiness to re-invent one-self on a regular basis. Our interviews also revealed that the occupational background of technology transfer experts is extremely diverse, mirroring both various entry paths into technology transfer and the division of work typical in transfer activities. Some were recruited with the qualification to perform specialist work, e.g. in patent law or licensing activities. Others were hired into technology transfer organizations because their credentials matched the need of transfer offices to have same-discipline representatives for the dialogue with researchers and faculty. Another group, made the transition to technology transfer from a business background, often in academic or university spin-offs. In sum, before entering the field, almost all interviewees had acquired scientific credentials and / or experience with the university-industry-interface.

\section{I Entry Paths to Technology Transfer: Accidental, Strategic or Forced}

Like their occupational backgrounds, entry paths into technology transfer organizations are subject to considerable variation. Some experts started their careers as junior scientists, while others already had the experience of a career in science or business before moving into the field. We find three basic types of entry into technology transfer:

(i) The 'accidental mover': the first narrative revolves around 'slipping in', 'laterally moving in' or 'taking the chance' at the right moment. Patterns like these mainly exist at the periphery of transfer activities, i.e. the provision of legal or administrative services, rather than in its core, i.e. the evaluation of the commercial potential of research. Thus it is typical for 'accidental movers' entering technology transfer from a non-scientific professional background, sometimes with experience in owning a business, often with a degree in business administration. Career accounts in this group suggest that having established contact with an employer in technology transfer and having gained early insight into the field is not unusual and proves mutually beneficial.

(ii) The 'strategic mover': the second narrative underlines a deliberate decision for a job in technology transfer because interviewees did not want to take up a 'traditional' science career. Examples of such careers include early pathways into technology transfer organizations, for example working as an intern and successfully applying for a regular job afterwards, as well as later decisions, for example changing from a (successful) science career after finishing one's PhD. 'Strategic movers' are disproportionately male, usually have a distinct scientific background, and often obtained a Ph.D. in science or engineering before working in technology transfer. While these men (and few women) were explicit in the interview with regard to their move into technology transfer, they also discussed why a career in science was either not available or not attractive to them. Often they quoted the 'rules of engagement' in research to explain why they left after finishing their Ph.D. or working as a post-doc, i.e. that only "a minority [of peers] continued with an academic career". 'Strategic movers' were also painting a grim picture of career and job opportunities at universities and in academic research, for example regarding job security, mobility requirements, and - if these men were fathers - problems in reconciling work with family. Finally, among the 'strategic movers', we also found a minority of men and women who had experienced the collapse of businesses they owned, e.g. in the biotechnology sector, and who saw their career prospects better guarded in the quasi-public university technology transfer employment sector we examined. 
(iii) The 'forced mover': this category includes women (not men) who returned to the labour market after a career break and ended up in technology transfer. This profile figured prominently among the senior employees interviewed. Although they often claimed to be a "dedicated scientist" with experience in basic and applied research at several institutes and in various projects, they could not continue a more traditional scientific career, either because they did not find a new contract in the field, or because their family obligations made a further research career impossible (at least from their perspective). For example, one female scientist turned to technology transfer for a tenured job to reconcile the double burden of work with domestic obligations. Another female scientist had worked several years in a post-doc position at a research institute before taking parental leave for several years. After returning to her job, she had to leave soon due to legal regulations allowing employment in science on fixed-term contracts in Germany only for a total of twelve years. These 'career break' patterns indicate that technology transfer provides options for scientists who have been actively engaged in research, but could not make their way up the ladder in academe. 'Career break stories' were emblematic for a significant faction of the females interviewed, whereas men typically moved into technology transfer without career interruption.

\subsection{Working in Technology Transfer: Career or Career Break?}

Based on these entry types, our results suggest that working in technology transfer may be a springboard for some, while for others it is a possibility to return to work in an environment that is neither 'pure' science, nor 'pure' management. A third group appreciated their current jobs in technology transfer as second-best - a compromise at best, but not a (future) career.

To many women, working in technology transfer appears to be a "perfect combination", particularly if they have taken a career break for childcare reasons, allowing them to stay close to the research and development sector without being actively engaged in a scientific career. Women in the group of 'forced movers', however, consider technology transfer to be "an interesting task, but not a career", because to them "a career would have been within science" and a job in technology transfer is "not so much the absolute peak of a career". In contrast, female professionals without a career break rate their current work more positive. Usually, these women are childless and in earlier phases of their professional lives - thus, they paint their current employment in brighter colours. Regarding career prospects, experience from both worlds - research and transfer work - is seen as providing opportunities in other fields. One female expert claimed that since "we have done so many different things, and also have exploited things by ourselves - even to a limited extent - I simply think the range [of skills] is very broad and especially for small firms you are really very attractive in principle. Because you are so skilled and can really perform in that kind of set up."

In contrast, our male interviewees neither evoked the science career to point at deficits in careers in technology transfer, nor did they see their current employment as 'second best'. Rather, these men tend to see their employment in technology transfer as a valuable interlude on their way up, maybe in a job in private business, maybe as management consultant. From this perspective, technology transfer offers an opportunity to extend one's networks, acquire additional qualifications, and develop valuable marketing and service skills. We found this 'male' perspective particularly in the group of 'strategic movers'. Career accounts of this type are built upon a growing distance to a career in science rather than a proximity to the business world - although most 'strategic movers' display a managerial 'habitus' and entrepreneurial spirit. At the time of our interviews, most interviewees in this group worked the middle ground between science and management, a "niche existence" now, pioneering at a frontier with the "potential for significant growth of the need for supporting institutions and the service jobs that come with it in science" in the future. However, they were also eager to underline their readiness to leave once another - probably more lucrative - opportunity would come along.

\subsection{Careers in Technology Transfer: A Double- Edged Sword}

In this final section we refer to two issues that were predominantly addressed by the women we interviewed, but not by their male colleagues, as two key dimensions of technology transfer careers, namely part-time work and the reconciliation of work with domestic responsibilities. 
The need for flexibility and the difficulty of coping with a demanding and responsible work in other fields figured prominently among the reasons provided by the female interviewees to explain the high percentage of women working in technology transfer organizations - especially when compared to careers in science. We found this pattern also in the career accounts of our female interviewees: a majority of mothers in our sample typically left their former job(s) at least for a while, and came to work in technology transfer later. Usually, they started on a part-time basis in order to spend more time with their children, regardless of the fact that other arrangements would have been possible, and even if it was detrimental to their careers or if they were overqualified for their current job in a technology transfer organization. At the same time, these women were clearly aware of expectations and labeling processes associated with their part-time status.

The narrative evoked by part-time working mothers regarding their current jobs was that of a "compromise". For some mothers it is a compromise, because following a (scientific) career without interruption to them was neither desirable, nor compatible with starting a family. Those interviewees who involuntarily sacrificed their careers in science for family obligations also evoked the term "compromise". Hence most interviewees mentioned that working in a technology transfer organization is "at least science-related" and that they enjoy working in a quasi-scientific environment. One female interviewee pointed out that her job is a temporary solution until her children become older so that she can return to do research full-time. Others were openly addressing the issue that working in a technology transfer organization would "never satisfy a devoted scientist or could be a substitute to a career in the private sector".

Despite their heterogeneous careers and the variety of jobs and tasks performed, most women we interviewed thought that their career would have looked entirely different had they been a man, claiming that they would not have had to take a career break. However, only one woman believed she would have stayed in science. Another woman explained that it was "expected" that men work full-time while employers were appreciative of women searching for a part-time job. Some women working in the public sector stressed that they applied for their jobs because of the family-friendly working conditions typical here. To men, according to one interviewee, this aspect is irrelevant when searching for a job.

\section{Conclusions}

In this paper, we explore the entries and subsequent careers of men and women working in technology transfer in Germany. We show that technology transfer in Germany is almost perfectly gender balanced on the surface, but with marked gender differences between and within the different transfer organizations we studied. Overall, the share of women among staff in technology transfer organizations in Germany is higher than the share of women among academics or faculty at the respective institutions. In within-field comparison, however, the proportion female is particularly low in the transfer activities of the prestigious German umbrella organizations, probably reflecting a focus on the core activities of patenting and licensing, fields where men tend traditionally to be better represented than women in Germany. Another explanation could be the lower representation of women in the German non-university research sector, lowering the chances of finding eligible women in the pool of female scientists. Finally, the organization of technology transfer is vital politically to umbrella organizations in generating revenues as a response to public funding, and in attracting scientists who might consider the extent of transfer activities a significant factor in hiring negotiations. Hence, technology transfer in umbrella organizations is more professionalized than in German universities, and is sometimes set up to circumvent the boundaries characteristic of the public service in Germany, for example regarding legal status (limited liability companies) and salary structure - characteristics that might draw a larger pool of people to technology transfer in general, and more men in particular.

In terms of entry and occupational background of interviewees in the organizations explored, men and women alike evoked pictures of the staff as a 'motley crew' - teams of diverse people, coming from various disciplines with different backgrounds and experiences. Of the three types of entry distilled, 'accidental movers' describes men and women who came to work in technology transfer from an academic but mostly non-scientific background, entering the field primarily by chance. In contrast, 'strategic movers' are men and women who decided to enter the field, mostly after pursuing a career in science. Finally, 
'forced movers' are characterized by a career break followed by employment in technology transfer. Regarding their gender composition, the first type of entry is balanced, the second type is predominantly male, and the third type exclusively female. The motifs of 'forced movers' thus reflect that, in Germany, men rarely take career breaks, a notoriously deficient provision of childcare facilities, generous maternity regulations together with the readiness of employers to hire mothers in part-time work. Against this background, 'strategic movers' to technology transfer are mostly male, probably mirroring their reality of wider employment and career opportunities beyond a career in science because they make the transition from the science system to technology transfer with more resources and hence confidence than women scientists, e.g. in terms of networks, visibility, and external exposure (Fuchs et al. 200I).

Indeed across entry types we found that women tend to consider career prospects in technology transfer of temporary nature and 'second best', especially when compared to a science career. Men also take a career in science as a point of reference in their career accounts. However, they portray their careers in an entrepreneurial spirit, explaining and justifying their decision to move into technology transfer as a strategic choice against the background of a career in science. Rather than male braggadocio, and given that almost half of the women we interviewed are working part-time, the intersection of 'career' and 'flexibility' in technology transfer together with a considerable workload then becomes a double-edged sword. Technology transfer in Germany offers responsible and flexible work and the opportunity to balance career and family to all. However, female scientists disproportionately make use of this opportunity, thus amplifying the potential gender bias in German technology transfer by running the danger of being expelled to the less rewarding jobs and organizations in the field.

Do women in Germany reappear successfully in the interface professions between science and the economy, then? While our results present a snapshot of events rather than a full-length movie, we indeed find that German technology transfer organizations exhibit a considerable proportion of females within their ranks, signaling opportunities and gains realized by female professionals and scientists. While organizational structures in technology transfer in Germany appear not to have coagulated to a particular gender structure yet, although we find women to be less well represented among the staff of more prestigious transfer institutions. Of more concern should be the lack of career opportunities and the vague occupational prospects currently colouring the career accounts of those employed in the field. While it is possible, that this is a mere reflection of the still transitory state of the field, it may also reflect a lack of institutional commitment on the side of universities to technology transfer organizations, thus rendering fragile women's gains in the field in particular.

\section{Acknowledge}

The authors gratefully acknowledge the support of the European Commission's 6th framework programme in research (Science and Society). We want to thank three anonymous reviewers for their helpful comments and Stefanie Bode for her assistance.

\section{References}

BARON, J.N., Hannan, M.T., Hsu, G., Kocak, O. (2002). Gender and the Organization-Building Process in Young High-Tech Firms. Pp. 245-273. In: Guillén, M.F., Collins, R., England, P., Meyer M. (eds). The New Economic Sociology, Russell Sage Foundation, New York.

BARON, J.N., Hannan, M.T., Hsu, G., Kocak, Ö. (2007). In the Company of Women. Gender Inequality and the Logic of Bureaucracy in Start-Up Firms. Work and Occupations, 34, 35-66.

CORLEY, E., Gaughan, M. (2005). Scientists' Participation in University Research Centers: What are the Gender Differences? Journal of Technology Transfer, 30, 37I-38I.

CROSBY, O. (2002). New and Emerging Occupations. Occupational Outlook Quarterly, Fall 2002, 17-25.

CRESPI, G.A., Geuna, A., Nesta, L. (2007). The Mobility of University Investors in Europe. Journal of Technology Transfer, 32, 195-215.

ETZKOWITZ, H., Fuchs, S., Gupta, N., Kemelgor, C., Ranga, M. (2008). The Coming Gender Revolution in Science. Pp. 403-428. In: Hacket, E.J., Amsterdamska, O., Lynch, M., Wajcman, J. (eds.). The Handbook of Science and Technology Studies, Third Edition. MIT Press Cambridge. 
FUCHS, S., Stebut, J., Allmendinger, J. (200I). Gender, Science, and Scientific Organisations in Germany. Minerva, 39, S.I75-20I.

KRÜCKEN, G. (2003). Learning the 'New, New Thing': On the Role of Path Dependency in University Structures. Higher Education, 46, 315-339.

KRÜCKEN, G., Meier, F., Müller, A. (2007). Information, cooperation and the blurring of boundaries - technology transfer in German and American discourses. Higher Education, 53, 675-696.

LEGAULT, M.-J., Chasserio, S. (2006). La gestion de projet dans les services technologiques aux enterprises et ses effets différenciés selon le genre. Regards sur le travail, $2 / 3$, 2-18.

LEYDESDORFF, L., Etzkowitz, H. (1998). The Triple Helix as a Model for Innovation Studies. Science and Public Policy, 25, 195-203.

MARKMAN, G.D., Gianiodis, P.T., Phan P.H., Balkin, D.B. (2005). Innovation speed: Transferring University Technology to Market. Research Policy, 34, 1058- 075.

MEUSER, M., Nagel, U. (1994). Expertenwissen und Experteninterview. Pp. 180-192. In: Hitzler, R., Honer, A., Maeder, Chr. (ed.). Expertenwissen. Westdeutscher Verlag, Opladen.

MOYSER, G. (1988). Non-standardized Interviewing in Elite Research. Studies in Qualitative Methodology, I, 109136.

MURRAY, F., Graham, L. (2007). Buying Science and Selling Science: Gender Differences in the Market for Commercial Science. Industrial and Corporate Change, 16, 657-689.

OWEN-SMITH, J. (2007). Where Does the Professional Knowledge Come From? Licensing Talk, Problem Resolution, and Rationalization in University Technology Transfer. Unpublished manuscript.

ROTHAERMEL, F.T., Agung, S.D., Jiang, L. (2007). University entrepreneurship: a taxonomy of the literature. Industrial and Corporate Change, 16, 691-791.
SIEGEL, D.S., Waldman, D.A. Link, A.N. (2003). Assessing the Impact of Organizational Practices on the Productivity of University Technology Transfer Offices: An Exploratory Study. Research Policy, 32, 27-48.

SIEGEL, D.S., Wright, M., Locke, A. (2007). The Rise of Entrepreneurial Activity at Universities: Organizational and Societal Implications. Industrial and Corporate Change, 16, 489-504.

SMITH-DOERR, L. (2004a). Women's Work: Gender Equality vs. Hierarchy in the Life Sciences. Lynne Rienner, Boulder, co.

SMITH-DOERR, L.I (2004b). Flexibility and Fairness: Effects of the Network Form of Organization on Gender Equity in Life Science Careers. Sociological Perspectives, 47, 25-54.

STEPHAN, P.E., El-Ganainy, A. (2007). The Entrepreneurial Puzzle: Explaining the Gender Gap. Journal of Technology Transfer, 32, 475-487.

THURSBY, J.G., Thursby, M.C. (2005). Gender Patechnology transfererns of Research and Licensing Acitivity of Science and Engineering Faculty. Journal of Technology Transfer, 30, 343-353.

THURSBY, J., Fuller, A.W., Thursby, M. (2009). US Faculty Patenting: Inside and Outside the University. Research Policy, 38, 14-25.

VALGAEREN, E. (2005). Gender Aspects of the Nomadic Career: Career Trajectories in the ICT-sector. htechnologytransferp://uhdspace.uhasselt.be/dspace/ bitstream/I942/9 I I/I/T088\%20_paper\%20stocholm\%20Elk e\%20Valgaeren_.pdf.

WHITTINGTON, B.W., Smith-Doerr, L. (2005). Gender and Commercial Science: Women's Patenting in the Life Sciences. Journal of Technology Transfer, 30, 355-370. 